\title{
New Insight in Human Lactonase PON2
}

\author{
Giuseppe Manco* \\ Istituto di Biochimica delle Proteine, Consiglio Nazionale delle Ricerche, Italia
}

Received: September 29, 2017; Published: October 10, 2017

*Corresponding author: Giuseppe Manco, Istituto di Biochimica delle Proteine, Consiglio Nazionale delle Ricerche, Via P. Castellino 111, 80131, Napoli, Italia

\section{Mini Review}

It is well established that oxidative stress from mitochondria plays an important role in apoptosis and also leads to premature aging and cancer [1]. There is growing scientific consensus that proteins with antioxidative functions, such as paraoxonases, can lower the incidence of these diseases. The paraoxonase (PON) gene family consists of three members: PON1, PON2, and PON3. PON genes are located in a gene cluster on chromosome 7q21.3-22.1 in human [2] and show about $70 \%$ sequence identity among them [3]. PON2 is a calcium-dependent glycoprotein of about $44 \mathrm{kDa}$, expressed ubiquitously, and associated with plasma membrane fractions. Recently, it has been demonstrated that PON2 is a type II Tran membrane protein, with its N-terminal region identified as a single Transmembrane domain, whereas the catalytic domain, corresponds to the C-terminus, located extracellularly to counteract lipid per oxidation [4].

PON2 has two main activities: a calcium-dependent hydrolytic activity, involved mainly in the hydrolysis of lactones, esters and aryl esters [2] and a redox function, which reduces the levels of ROS (reactive oxygen species) thus curbing cell oxidative stress and therefore displaying an anti-apoptotic effect. No clues are available about the molecular basis of this anti-ROS activity except the demonstration that PON2 can bind ubiquinone (coenzyme Q10) with high affinity only in the presence of Ca2+ [5]. In doing so coenzyme Q10 is substracted from interaction with 02 and production of ROS.

Unlike PON1 and PON3, PON2 is an intracellular protein, expressed in a wide range of cell types, including pancreatic beta cells. Importantly, polymorphisms in the PON2 protein (S311C and A148G) have been associated by several studies with diabetes and its complications. Although a genetic association between PON2 and these conditions has been shown, the exact function of PON2 in humans is not known. It has been shown that all of the PONs can inactivate the lactone 3-Oxo-C12-HSL [2,6-8]. Among PONs, PON2 has the greatest lactonase activity against the bacterial quorumsensing (QS) molecules [2,9]. QS Is an interbacterial mode of communication accomplished through the coordinated production, secretion, and detection of chemical signals (QS signals) that trigger the expression of specific bacterial genes. The QS signals self-produced by P. aeruginosa are in the form of small molecules, termed acyl- homoserine lactones (acyl-HSLs) [10] among which 3-0xo-C12-HSL is the master regulator [11]. It has been demonstrated that PON2 responds to the bacterial quorormone 3-0xo-C12-acyl homoserine lactone by a rapid decrease of the lactonase activity via a putative post-translational modification (PTM) [12]. Therefore, Pseudomonas produced 3-Oxo-C12-HSL, organizes from one side the coordinated attack of bacterial cells against human tissues and on the other curbs the human defences by blocking PON2 activity, which is thought to represent the first line of defense against infections [9].

PON2 being located on cell surface [4] can rapidly clear out the 3-0xo-C12-HSL accumulating outside the cell and passing through the membrane. The increase in the concentration of the quorormone activates, at a certain threshold, the production of virulence factors and the formation of a biofilm [11]. It also diffuses inside the cells or binds specific receptors thereby activating processes that are different in different cell types [13]. Relevant is the effect on NF$\mathrm{kB}$ signaling through which 3-0xo-C12-HSL attenuates the innate immune system to establish and maintain local persistent infection in humans, for example, in cystic fibrosis patients [14].

Recently we discovered a new PTM of PON2 induced by 3-0xo-C12-HSL [15] namely the ubiquitination of Lys 144 (168 in the paper) that may be of physiological importance because it decreases the PON2 activity. Moreover we have shown that PON2 is able to interfere efficiently with the formation of the biofilm in vitro [15]. These experiments were conducted by expressing an engineered version of PON2 in E. coli and renaturing it from inclusion bodies. We also suggested in this way that glycosylation of PON2 is not important for activity but likely for stability. Teiber [16] reported that phosphorylation of Ser36 is necessary for activity. This is in contrast with our data: our rPON2 made in E. coli is active and devoid of phosphorylation also because the deletion at the N-terminus includes Ser36. In any case 3-Oxo-C12-HSL does not seem to act via this phosphorylation site [16]. 
In previously published large scale mass experiments Tyr346 has been found phosphorylated [17]. Mutants at that position maintain activity and are still inactivated by 3-0xo-C12-HSL [16]. In our effort to clarify the role of PON2 we are focusing also on expression regulation. In a follows up of our previous work [18] we identified in the 3'UTRs of some MHCII genes a quite well conserved sequence, already suggested in a recent paper as a putative regulative signal [19]. The sequence was shared by a cluster of a limited group of genes. In the same database we looked for the Table 1. presence of signals downstream of the PON2 gene. There was just one occurrence for PON2. The identified sequence was a 12mer: TTTCCTTAAAAT identifying a cluster of 21 genes. This sequence does not overlap with any MREs. The interesting aspect of this finding is that most of these genes are functionally related (based on information at www.genecards.org) and involved in apoptosis, proteosomal degradation (ubiquitinylation) and DNA repair (Table 1). We are currently analysing the involvement of these genes in regulation and physiology of PON2.

\begin{tabular}{|c|c|}
\hline \multicolumn{2}{|r|}{ Table } \\
\hline Gene & Function \\
\hline TRIM33 & Acts as an E3 ubiquitin-protein ligase \\
\hline RAB40B & E3 ubiquitin ligase complex which mediates the ubiquitination and subsequent proteasomal degradation of target proteins. \\
\hline BIRC3 & Apoptotic suppressor. Acts as an E3 ubiquitin-protein ligase regulating NF-kappa-B signaling. \\
\hline RNF11 & $\begin{array}{l}\text { Essential component of a ubiquitin-editing protein complex, comprising also TNFAIP3, ITCH and TAX1BP1, that ensures the } \\
\text { transient nature of inflammatory signaling pathways. }\end{array}$ \\
\hline MAP3K2 & Regulates the JNK and ERK5 pathways by phosphorylating and activating MAP2K5 and MAP2K7. \\
\hline WDR36 & Involved in T cell activation and highly co-regulated with IL2. \\
\hline LIN28B & Acts as a suppressor of microRNA (miRNA) biogenesis. \\
\hline WTAP & $\begin{array}{l}\text { Regulates G2/M cell-cycle transition by binding to the 3' UTR of CCNA2 (cyclinA2), which enhances its stability. Impairs WT1 } \\
\text { DNA-binding ability and inhibits expression of WT1 target genes. May be involved in mRNA splicing regulation. }\end{array}$ \\
\hline SRPK2 & $\begin{array}{l}\text { Phosphorylates RS domain-containing proteins, such as SFRS1 and SFRS2 on serine residues. Role in spliceosome assembly and } \\
\text { in mediating the trafficking of splicing factors. }\end{array}$ \\
\hline RRM2B & Plays a pivotal role in cell survival by repairing damaged DNA in a p53/TP53-dependent manner. \\
\hline LRRC19 & $\begin{array}{l}\text { A novel member of the leucine-rich repeat protein family activates NF-kappaB and induces expression of proinflammatory } \\
\text { cytokines. LRRC19 may play an important role in inducing innate immune responses in certain tissues such as the kidney. }\end{array}$ \\
\hline CD93 & $\begin{array}{l}\text { Receptor (or element of a larger receptor complex) for C1q, mannose-binding lectin (MBL2) and pulmonary surfactant protein } \\
\text { A (SPA). May mediate the enhancement of phagocytosis in monocytes and macrophages upon interaction with soluble defense } \\
\text { collagens. Now is thought to instead be involved in intercellular adhesion and in the clearance of apoptotic cells. }\end{array}$ \\
\hline NEXN & Involved in regulating cell migration through association with the actin cytoskeleton. \\
\hline TTC22 & $\begin{array}{c}\text { Protein with seven tetratricopeptide (TPR) repeats. TPR repeats are found in a variety of proteins and may mediate protein } \\
\text { protein interactions and chaperone activity. }\end{array}$ \\
\hline MGAT4A & $\begin{array}{l}\text { This gene encodes a key glycosyl transferase that regulates the formation of tri and multiantennary branching structures in the } \\
\text { Golgi apparatus. }\end{array}$ \\
\hline R0B01 & $\begin{array}{l}\text { The product of this gene is a member of the immunoglobulin gene super family and encodes an integral membrane protein that } \\
\text { functions in axon guidance and neuronal precursor cell migration. This receptor is activated by SLIT-family proteins, resulting in } \\
\text { a repulsive effect on glioma cell guidance in the developing brain. }\end{array}$ \\
\hline $\mathrm{CPE}$ & $\begin{array}{c}\text { This peripheral membrane protein cleaves C-terminal amino acid residues and is involved in the biosynthesis of peptide } \\
\text { hormones and neurotransmitters, including insulin. }\end{array}$ \\
\hline
\end{tabular}

\section{Acknowledgement}

This work has been supported by CNR project "Interomics" to G.M.

\section{References}

1. Li X, Fang P, Mai J, Choi ET, Wang H, et al. (2013) Targeting mitochondrial reactive oxygen species as novel therapy for inflammatory diseases and cancers. J Hematol Oncol 6: 19.

2. Draganov DI, Teiber JF, Speelman A, Osawa Y, Sunahara R, et al. (2005) Human paraoxonases (PON1, PON2, and PON3) are lactonases with overlapping and distinct substrate specificities. Journal of Lipid Research 46(6): 1239-1247.
3. Sorenson RC, Primo-Parmo SL, Camper SA, La Du BN (1995) the genetic mapping and gene structure of mouse paraoxonase/arylesterase. Genomics 30(3): 431-438.

4. Hagmann H, Kuczkowski A, Ruehl M, Lamkemeyer T, Brodesser S, et al. (2014) Breaking the chain at membrane: paraoxonase 2 counteracts lipids peroxidation at the plasma membrane. FASEB Journal 28(4): $1769-1779$.

5. Devarajan A, Bourquard N, Hama S, Navab M, Grijalva V, et al. (2011) Paraoxonase 2 deficiency alters mitochondrial function and exacerbates the development of atherosclerosis. Antioxid Redox Signal 14(3): 341351.

6. Ozer EA, Pezzulo A, Shih DM, Chun C, Furlong C, et al. (2005) Human and murine paraoxonase 1 are host modulators of Pseudomonas aeruginosa quorum-sensing. FEMS Microbiol Lett 253: 29-37. 
7. Yang F, Wang LH, Wang J, Dong YH, Hu JY, et al. (2005) Quorum quenching enzyme activity is widely conserved in the sera of mammalian species. FEBS Lett 579(17): 3713-3717.

8. Stoltz DA, Ozer EA, Recker TJ, Estin M, Yang X, et al. (2009) A common mutation in paraoxonase-2 results in impaired lactonase activity. J Biol Chem 284: 35564-35571.

9. Teiber JF, Horke S, Haines DC, Chowdhary PK, Xiao J, et al. (2008) Dominant role of paraoxonases in inactivation of the Pseudomonas aeruginosa quorum-sensing signal $\mathrm{N}$-(3-oxododecanoyl)-L-homoserine lactone. Infect Immun 76(6): 2512-2519.

10. Dong YH, Zhang LH (2005) Quorum sensing and quorum-quenching enzymes. J Microbiol 43: 101-109.

11. Deepak Balasubramanian, Lisa Schneper, Hansi Kumari, Kalai Mathee (2013) A dynamic and intricate regulatory network determines Pseudomonas aeruginosa virulence. Nucleic Acids Research 41(1): 1-20.

12. Horke S, Witte I, Altenhofer S, Wilgenbus P, Goldeck M, et al. (2010) Paraoxonase 2 is down-regulated by the Pseudomonas aeruginosa quorum sensing signal $\mathrm{N}$-(3-oxododecanoyl)-L- homoserine lactone and attenuates oxidative stress induced by pyocyanin. Biochem J 426(1): 7383.

13. Liu, Chan, Chang (2015) Modulation of Host Biology by Pseudomonas aeruginosa Quorum Sensing Signal Molecules: Messengers or Traitors. Front Microbiol.
14. Vladimir V Kravchenko, Gunnar F Kaufmann, John C Mathison, David A Scott, Alexander Z Katz, et al. (2008) Modulation of Gene Expression via Disruption of NF-kB Signaling by a Bacterial Small Molecule. Science 321(5886): 259-261.

15. Mandrich L, Cerreta M, Manco G (2015) An Engineered Version of Human PON2 Opens the Way to Understand the Role of Its Post-Translational Modifications in Modulating Catalytic Activity. PLoS One 10: 10(12): e0144579.

16. Teiber J (2013) Annual report Grant Award N. W81XWH-12-2-0091.

17. Rikova K, Guo A, Zeng Q, Possemato A, Yu J, et al. (2007) Global survey of phosphotyrosine signaling identifies oncogenic kinases in lung cancer. Cell 131(6): 1190-1203.

18. Corso C, Pisapia L, Citro A, Cicatiello V, Barba P, et al. (2011) EBP1 and DRBP76/NF90 binding proteins are included in the major histocompatibility complex class II RNA operon. Nucleic Acids Res. 39(16): 7263-7275.

19. Yoon K, Ko D, Doderer M, Livi CB, Penalva LOF (2008) Over-represented sequences located on 3' UTRs are potentially involved in regulatory functions. RNA Biol 5(4): 255-262.

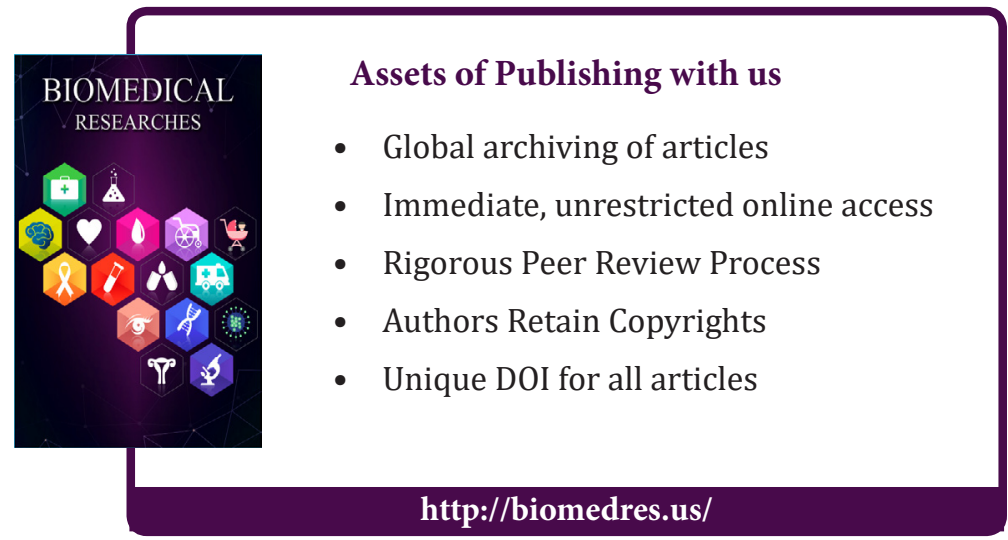

